\title{
Social Networking Sites Habits and Addiction Among Adolescents in Klang Valley
}

\author{
Yazriwati Yahya $^{1 *}$, Nor Zairah Ab. Rahim ${ }^{2}$, Roslina Ibrahim ${ }^{3}$, Nurazean Maarop ${ }^{4}$, Haslina Md Sarkan ${ }^{5}$, Suriayati \\ Chuprat $^{6}$ \\ Razak Faculty of Technology and Informatics \\ Universiti Teknologi Malaysia \\ Jalan Sultan Yahaya Petra, 54100, Kuala Lumpur, Malaysia
}

\begin{abstract}
Social networking sites (SNS) is a very popular application in today's world society. SNS, to certain extent has change the way people communicate with each other. This kind of technology has become a trend among the users regardless the impact of the technology to the users either positive or negative. The level of SNS usage among the adolescents has started to raise concern among the parents and also the society. SNS addictions are becoming problematic in certain countries especially in United States and lately this issue has started to spread all over the world. Malaysia is also one of the country affected with SNS addiction. SNS addiction is not an isolated phenomenon as it is started from high engagement on the SNS usage and it originates from habitual behavior. Therefore, it is important to seek and understand habit and addiction of SNS among adolescents in Malaysia. The purpose of this study is to analyze and explore the usage of SNS among the adolescents in Malaysia, specifically in Klang Valley. It examines the SNS usage behavioral, which is habit and addiction. The data was collected from a sample of 60 respondents using an online survey. The data were analyzed using SPSS for descriptive analysis. From the analysis, it was found that most of the adolescents used SNS in daily basis and majority of them use it for more than two hours per day. Patterns on habits and addiction on the SNS usage shows that some adolescents experienced certain habit and addiction behavior.
\end{abstract}

Keywords-Social networking sites; habit behavior; addiction behavior; SNS usage

\section{INTRODUCTION}

The Internet World Statistics [1] demonstrates that Malaysia is among the 10 Asia Top Internet Countries with more than 20 million Internet users. As indicated by Malaysian Communications Multimedia Commission (MCMC), the Internet Addiction (IA) and digital security issue are influencing youths in urban territories, as well as understudies in rustic zones, particularly in schools where free portable workstations and Internet access are given. Other than influencing their psychological well-being, the Internet fixation has transformed the physical activity exercises into virtual activity among the youngsters. Fixations or preoccupations with the Internet encourages a hazardous kind of addiction today. According to psychiatric consultant Dr Muhammad Muhsin Ahmad, Deputy Chief Coordinator at Centre of Addiction Sciences, Universiti Malaya, [2] "Malaysia has high chances of developing a segment society that are Internet addicts in the near future".
Recently, SNS usages, which are part of the Internet fixation, have captured the scholar's attention. In Digital SouthEast Asia 2017 [3] report, the total number of active users of social media in Malaysia has reached 22 million. According to Shin \& Ismail [4] Malaysian youth are active SNS users spending an average of 19 hours online per week, and $20 \%$ of Facebook users of the country are younger than 18. While most social media platforms set a minimum age of 13 to sign up on their sites, Cyber-Security Malaysia's nationwide survey of over 8,000 primary and secondary students found that almost half of the pupils aged between 7 and 9, have social media accounts. According to a local newspaper, Sunday Star in its report on Oct 8, 2017, this percentage went up to $67 \%$ for children aged between 10 and 12.

Many people tend to check their SNS from the moment they woke up early in the morning. Information comes straight to us without our hassle to find them. This shows that how dependent our society to the SNS. The engagement in SNS has shown some positive implication such as easy and fast communication with friends and family; able to update people's life and maintain social relationship; and also support positive behaviours such as self-promotion and self-disclosure [5]. Nevertheless, some people spend too much time on the SNS platforms and experience the negative outcome without them realizing it [6]. The positive and negative outcomes of the SNS usage are resulted from the habitual behaviour. A stronger SNS habit may lead to pathological problems such as addiction. Researchers also have suggested that the excessive use of SNS has started to be one of major concern among the adults and also may be particularly problematic to youngsters as well [7].

SNS addiction may contribute negative effect to adolescents. Perceived low self-esteem which then lead to low well-being is one of the effects due to the negative comments from friends about their SNS profile [8]. Lower grades in academic as a result of poor time management for adolescents who spent more time on the SNS compared to those who did not use SNS [9]. Apart from that, other negative behavior such as stealing information, cyber bulling, contacting strangers and also spread false information was also triggered to be the causes the SNS addiction[10][11]. An article in The Star online newspaper dated January $5^{\text {th }} 2015$ has highlighted that Malaysians engaged for long hours on their SNS rather than meeting their friends' offline. They also tend to share 
everything about themselves on the SNS rather than having actual conversation with their families and friends. They did not realize that SNS have slowly destroyed their rapport with the families and friends. SNS also affect the academic growth among students since much of their time is spent staring at the screen [12]. Such behaviors may cause negative effects that will lead to further serious problems.

The aim of this paper is to focus on the SNS usage behavioural which is habit and addiction experience by the adolescents in Klang Valley area. Klang Valley is centered in the city of Kuala Lumpur in Malaysia and incorporates its connecting urban areas and towns in the province of Selangor. The paper will discuss on the SNS usage among the adolescents and also compare the SNS usage behavioural between age categories.

\section{RELATED WORKS}

\section{A. Platform of Social Networking Sites}

According to statistic portal on social media and networking sites in United States (US) [13], Snapchat, Facebook and Instagram are categorized to be the mostly used SNS platform among the adolescents in 2017 (see Fig. 1).

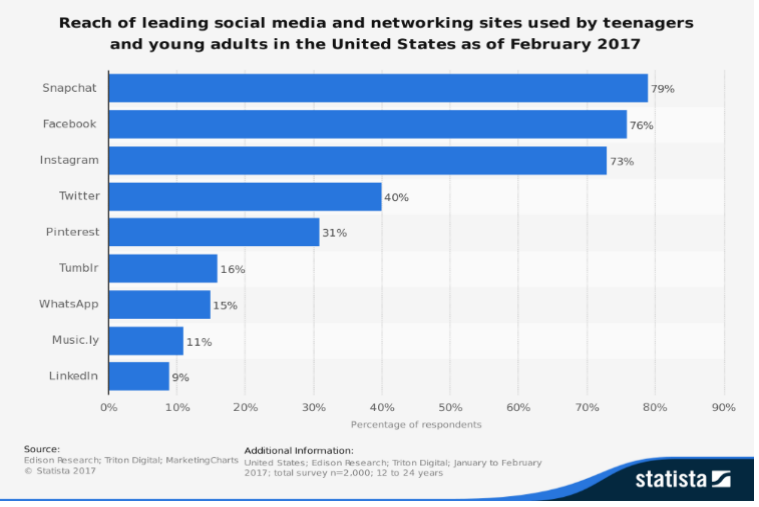

Fig. 1. Social media and networking sites used by adolescents in US [13].

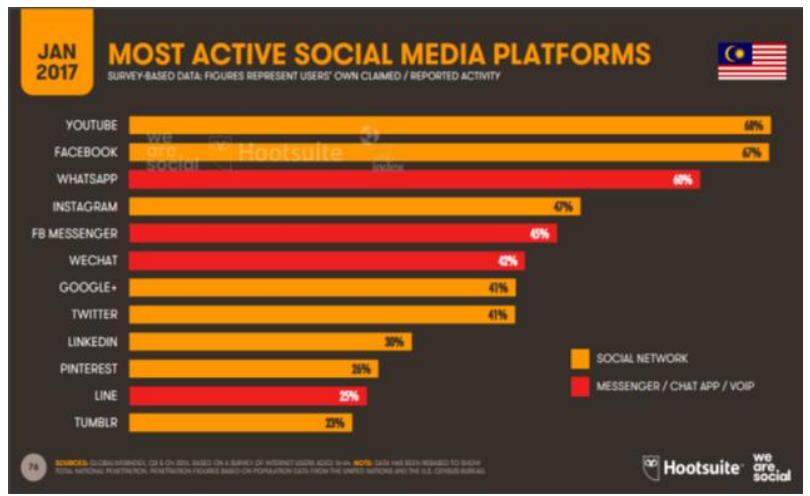

Fig. 2. The most active SNS and messenger application used in Malaysia [3].

In general, YouTube has dominated the SNS platforms used by Malaysians regardless adults or adolescents as depicted in Fig. 2.

Fig. 3 and 4 show the analysis of Facebook usage and Facebook user's profile. Even though the percentage of users' aged $13-17$ years in Malaysia is not as high as other age, it still contributes to the percentage of SNS use.

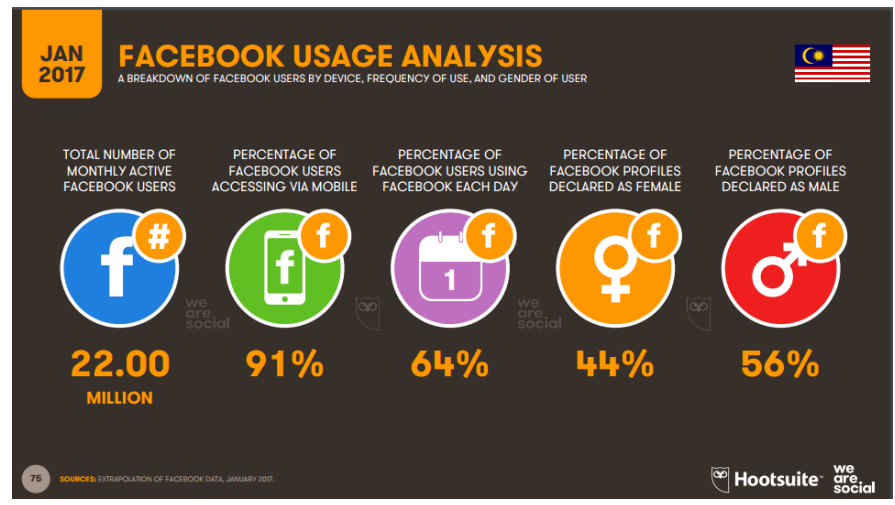

Fig. 3. Facebook usage analysis in Malaysia [3].

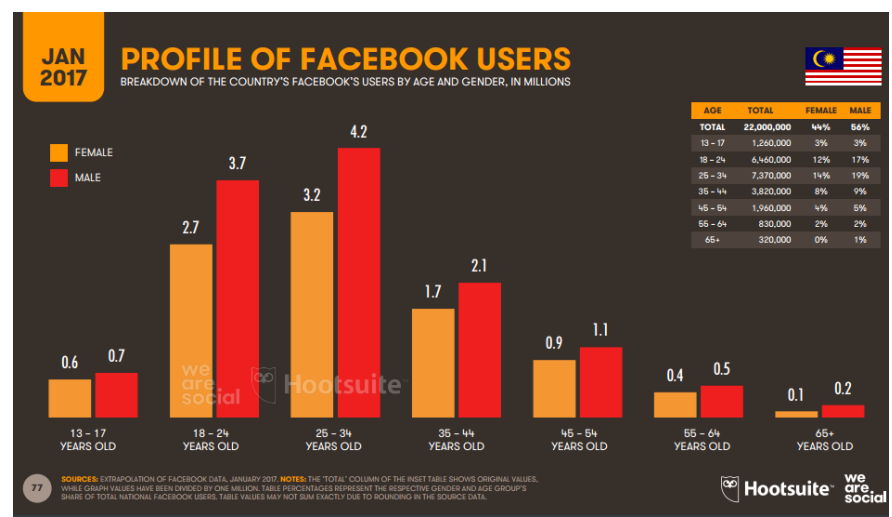

Fig. 4. Profile of Facebook users in Malaysia according to age and gender [3].

Professor Datuk Dr Chiam Heng Keng [14], a leading figure in child and adolescent psychology and early childhood education, said reports about adolescents turning to social media and destructive online games such as the Blue Whale game, which purportedly encouraged adolescents to end their lives as a way to solve their problems, is worrying. According to her, in today's society, many teenagers spend most of their times on the smartphone and Internet. This also has resulted the lack of ability for them to communicate face to face with other people. They probably cannot communicate with their parents, teachers or peers about their stress and fears, and are so desperate to be heard that they resort to the Internet. She said that the teenagers may feel frustrated with their lives, involved in love affairs and facing exams stress, making them believe that the help is available from their online friends.

\section{B. Habit Formation}

Based on prior research, the concept of habit is not new [15]. According to [16], habit has more influences when foreseeing repeated behavior rather than variables like intention or attitudes. Habit is a type of automatic action that needs deliberateness, mindfulness, and controllability, despite the fact that its effectiveness is high [17]. However, even though habit used to describe as a behaviour, it is actually not a behaviour in itself as it is a mental state that drives a person to perceive habit-related stimulus cues in order to achieve certain goals [16][18]. Hence, habitual behaviour is the action 
resulting from the cue. These cues can be times, places, specific situations, moods, goals, etc. [19]. For example, the tendency of a person's behavioural to check their SNS from the mobile phone after waking up. In the literature, habit and past behaviour were used equally. Past behaviour may turn into habit once it is successfully repeated over the time [20].

Habit is the outcome from the automatic process where once a habit is shaped; the individual will have less attention on their behavior performance and most likely to be involved with non-reflective cognitive processing [21][22]. The existing studies of habit are more focused on how IS habit is theorized and measures, plus with its relationship with continuance intention and IS continuance use [23][18]. Overall, IS researcher have come to one conclusion that if individuals are habitually performing a behavior such as using a SNS, the future behavior which is continued using SNS will be mostly controlled by habit instead of reasoned action.

The formation of habit was based on the action done repetitively without consciousness for a specific timeframe and normally for long term of period. It includes characteristic such as unintentional, uncontrollable, lack of awareness and efficiency [24]. Accordingly, people characterize their habits as an intentional sequence of behavior where to a certain period it is controllable, executed with less awareness and efficient [16].

\section{SNS Addiction Formation and Symptoms}

According to [25], the formations of SNS addiction are based on three theoretical perspectives: (1) the cognitive behavioral model; (2) the social skill model; (3) sociocognitive model. The cognitive behavioural model suggests that some SNS users can develop nonadaptive apprehension that could be caused by various environmental factors. For example, social isolation or lack of peer support, and lead to the development of nonadaptive obsessive use patterns. The social skill model highlights that people can be lacked of selfpresentational skills if they prefer online communication rather than face to face interactions. The socio-cognitive models emphasize that the obsessive behaviors are resulted from expectation of positives results combine with selfusefulness and weak self-control. [26] used this formation to prove that those who encounter transition from normal SNS use to problematic SNS use are usually use SNS to relieve stress, loneliness or depression. According to [27], frequent SNS users normally are not good at interacting face to face. Since SNS provides satisfaction and self-efficacy, these people tend to use SNS as frequent as they can which then causes many other problems such as ignoring relationship with family and friends or problems with study and at work.

Griffiths believes that any behavior that fulfill six components of addiction behavior or also known as addiction symptoms can be operationally defined as addiction [28]. The six symptoms are:

1) Salience: Salience happens when even if we do not use SNS at the moment, we are persistently keep on thinking about using it and anxiously waiting to use it as soon as possible. This reflects when SNS has becoming the most important agenda in our lives that dominates not just our thinking, but feelings and behavior as well.

2) Mood modification: Changing on the mood such as feelings of escape or upset as a result of consequence of social networking and can be seen as coping strategy.

3) Tolerance: In order to accomplish the previous mood modification effect, a huge amount of social networking activities are needed. This basically means that for people engaged in social networking, they gradually build up the amount of the time they spend social networking every day.

4) Withdrawal symptoms: When people fail to disengage with the social network because of certain reason, unpleasing feeling such as an adverse mood and irritations occurs.

5) Conflict: This refers to the conflicts between a person and those around that person (interpersonal conflict), conflicts with other activities (social life, hobbies, and interests), or from within the individual him or herself (e.g., subjective feelings of loss of control) that are concerned with spending too much time social networking.

6) Relapse: This is the tendency for repeated reversions to earlier patterns of excessive social networking to recur and for even the most extreme patterns typical of the height of excessive social networking to be quickly restored after periods of control.

These symptoms were used as benchmark by the psychology and clinical studies to identify the existence of SNS addiction among the SNS users. The addiction symptoms are very important to be recognized because if it is not to be treated will established negative effects among the SNS users.

Despite being a current topic, dependency on SNS, which may lead to excessive use usually, goes unnoticed by family members [29]. Even though SNS addiction studies have started to get scholars attention at the beginning of its introduction, but most of them were focused on adult users. SNS addiction studies on adolescents are still at early stage [10]. Studies on SNS Addiction among adolescents are more focused on the usage patterns [30], factors of SNS addiction [31] and negative consequences for being addicted [10] and all these studies concentrated on psychological and clinical perspective. Whilst, studies on SNS addiction from the perspective of hedonic information systems (IS) have emphasized more on the impact of addiction on SNS continuance intention of use [32][33].

\section{METHODOLOGY}

The methodology in this study was divided into three sections which are the participants, instrument and data analysis. The result of this particular study is descriptive in nature.

\section{A. Participants}

An online survey were created using Google form and link were distributed among parents in Klang Valley. Data were collected for 3 weeks and 60 responded answered were captured. The sample comprised $70 \%$ female and $30 \%$ male.

\section{B. Instrument}

Data were collected by means of an online survey 
developed by the researchers. The survey consisted of three sections. The first section contains on demographic information of the adolescents. The second section examines the use of SNS such as how long and how often adolescents view and access SNS and also, length of time spent in SNS. The third section was consisted of items related to SNS Usage behavioral such as habit and addiction. The addiction scales were extracted from the [34] study while the habit scales were retrieved from [23] study. The Cronbach's alpha reliability coefficient of this scale was 0.61 for addiction scale and 0.74 for habit.

\section{Data Analysis}

Data were collected using the developed scale. The data obtained by the survey was analysed using the SPSS program with the percentage, frequency, and statistical analysis techniques.

\section{FINDINGS AND DISCUSSIONS}

\section{A. Demographic Analysis}

A several demographic questions were used in the preliminary online survey and 60 feedbacks were recorded. Based on the results, a demographic profile data are retrieved. The respondents were categorized into two group of age, which are: Below 19 years and above 19 years. Respondents above 19 years are categorized as late adolescents or young adults. The survey was responded $70 \%$ by female and $30 \%$ by male (see Table I). Based on the analysis, $90 \%$ of the respondents used the SNS more than 4 years as displayed in the table and they accessed and viewed the SNS more on daily basis (Table II), which means that they apparently are quite familiar in using the SNS platform.

TABLE I. DEMOGRAPHIC ANALYSIS

\begin{tabular}{|c|c|c|}
\hline Variables & $\begin{array}{l}\text { N Respondents } \\
(\mathbf{N}=60)\end{array}$ & $\begin{array}{l}\text { Percentages } \\
(\%)\end{array}$ \\
\hline \multicolumn{3}{|l|}{ Gender } \\
\hline Female & 42 & 70 \\
\hline Male & 18 & 30 \\
\hline \multicolumn{3}{|l|}{ Age } \\
\hline$<19$ years & 41 & 32 \\
\hline$>19$ years & 19 & 68 \\
\hline \multicolumn{3}{|l|}{ Start Using SNS } \\
\hline$<6$ months & 2 & 0 \\
\hline 1- 2 years & 4 & 7 \\
\hline$>3$ years & 54 & 93 \\
\hline
\end{tabular}

\section{B. Time Spent on SNS}

The average time of spending on the SNS is more than two hours (see Table II). This result is in line with study by [4] that Malaysian youth are actually are active SNS users spending an average of 19 hours online per week.
TABLE II. SNS USAGE

\begin{tabular}{|c|c|c|}
\hline Variables & $\begin{array}{l}\text { N Respondents } \\
(\mathbf{N}=60)\end{array}$ & $\begin{array}{l}\text { Percentages } \\
(\%)\end{array}$ \\
\hline \multicolumn{3}{|l|}{ Access \& View } \\
\hline Daily & 53 & 88 \\
\hline Weekly & 6 & 10 \\
\hline Monthly & 1 & 2 \\
\hline \multicolumn{3}{|c|}{ Average Time Spend per day } \\
\hline $\begin{array}{l}<30 \\
\text { minutes }\end{array}$ & 17 & 28 \\
\hline 1 to 2 hour & 20 & 33 \\
\hline$>2$ hours & 23 & 39 \\
\hline \multicolumn{3}{|c|}{ The Most Used SNS ( Top 4) } \\
\hline Instagram & & 30 \\
\hline Facebook & & 21 \\
\hline Twitter & & 15 \\
\hline Snapchat & & 10 \\
\hline
\end{tabular}

The most popular SNS platform used based on this analysis is Instagram (30\%), followed by Facebook (21\%) and Twitter (15\%) as illustrated in Fig. 5. This is in line with Fig. 1 shows the most popular in United States (US) among adolescents are Snapchat, Facebook and Instagram. Even though the usage Snapchat platform in Malaysia is not as popular as in US, however, Facebook and Instagram are still on top of the list among Malaysia which is similar with US.

\section{SNS Platform}

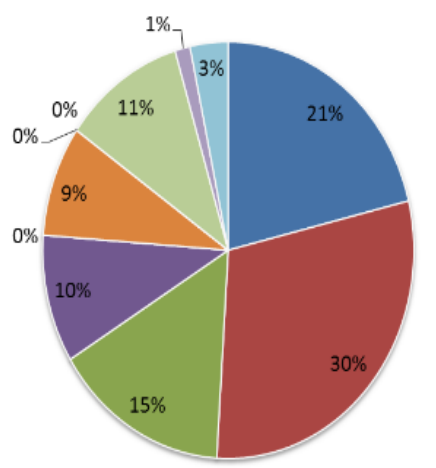

Fig. 5. The most used SNS platform.

\section{SNS Habit}

Three questions on SNS habit were highlighted in the survey which were adopted from [23]. The questions are:

HAB1. Using this SNS has become automatic to me.

Automatic here means something is done or occurring spontaneously, without thinking. Example given in the survey is "Once I reach home after school, automatically I will access my social networking sites".

HAB2. Using this SNS is natural habit to me. 
When using the SNS, it is naturally done without forcing.

$H A B 3$. When I want to interact with friends and relatives, using SNS is an obvious choice for me.

This means that SNS is main medium communication that will be used when it comes to communicate with friends and relatives.

Fig. 6 shows the result of mean, median and mod values together with percentage of habit item for construct habit. Items ranged from Strongly Disagree (1) to Strongly Agree (5). Based on the overall result, $63.4 \%$ agreed that using SNS is done automatically without hesitation. $51.7 \%$ also agreed that using SNS is natural for them. As for SNS is an obvious choice for main medium communication, $48.3 \%$ agreed that it is an obvious choice for medium interaction while $30.0 \%$ does not agree and $21.7 \%$ sometimes agreed. There are possibilities that they are using other medium communication besides SNS. The results suggested that about $50 \%$ to $60 \%$ of respondents found SNS is a natural to them and became a habit in their daily life.

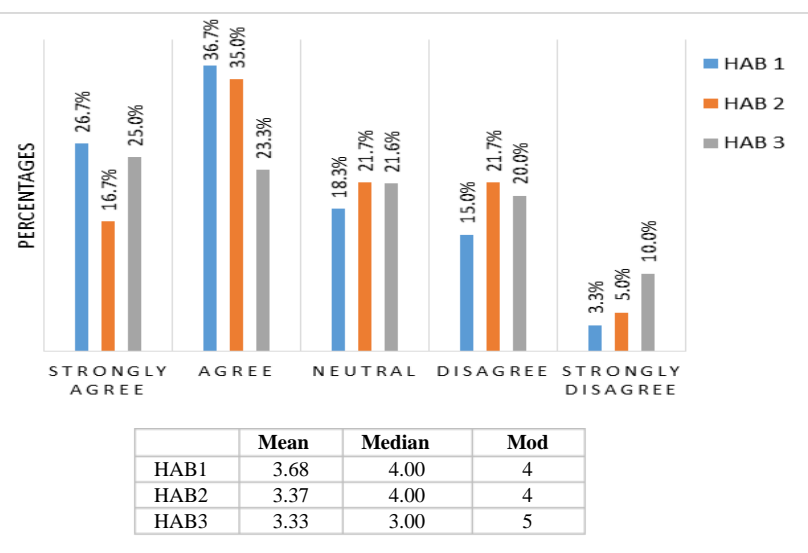

Fig. 6. Result of overall descriptive analysis on SNS habit

TABLE III. Result of DesCRIPTIVE ANAYLSIS BetweEn AgE AND Hab1 (AUTOMATIC USE)

\begin{tabular}{|c|c|c|c|c|c|c|c|}
\hline \multicolumn{8}{|c|}{ HAB1 } \\
\hline$A$ ge & & $\begin{array}{c}\text { Strongly } \\
\text { Disagre } \\
e\end{array}$ & $\begin{array}{c}\text { Disagre } \\
e\end{array}$ & Neutral & Agree & $\begin{array}{c}\text { Strongly } \\
\text { Agree }\end{array}$ & Total \\
\hline \multirow{2}{*}{$\begin{array}{l}<19 \\
\text { years }\end{array}$} & $f$ & 0 & 7 & 8 & 16 & 10 & 41 \\
\hline & $\%$ & 0.0 & 17.1 & 19.5 & 39.0 & 24.4 & 100.0 \\
\hline \multirow{4}{*}{$\begin{array}{l}>19 \\
\text { years }\end{array}$} & $f$ & 2 & 2 & 3 & 6 & 6 & 19 \\
\hline & $\%$ & 10.5 & 10.5 & 15.8 & 31.6 & 31.6 & 100.0 \\
\hline & Total $f$ & 2 & 9 & 11 & 22 & 16 & 60 \\
\hline & $\begin{array}{c}\text { Total } \\
\%\end{array}$ & 3.3 & 15.0 & 18.3 & 36.7 & 26.7 & 100.0 \\
\hline
\end{tabular}

Table III shows the cross tabulation between age categories with HAB1 (Automatic use) while Table IV shows the cross tabulation between age categories with HAB2 (Natural habit). From the tables, most of the respondents either below 19 years $(63 \%)$ or above 19 years $(63 \%)$ agreed that the SNS use is automatically or spontaneously done and has becoming a natural habit. Only 7 out of 41 respondents disagree that use of SNS is automatic to them while for respondents above 19 years, 4 out of 19 respondents disagree with the same statement. When behaviour becomes habitual, users tend to use the system automatically without going through the cognitive planning process.

TABLE IV. RESULT OF DESCRIPTIVE ANAYLSIS BETWEEN AGE AND HAB2 (NATURAL HABIT)

\begin{tabular}{|c|c|c|c|c|c|c|c|}
\hline \multicolumn{8}{|c|}{ HAB2 } \\
\hline Age & & $\begin{array}{c}\text { Strongly } \\
\text { Disagre } \\
\quad e\end{array}$ & $\begin{array}{c}\text { Disagre } \\
e\end{array}$ & Neutral & Agree & $\begin{array}{c}\text { Strongly } \\
\text { Agree }\end{array}$ & Total \\
\hline \multirow{2}{*}{$\begin{array}{l}<19 \\
\text { years }\end{array}$} & $f$ & 1 & 8 & 12 & 15 & 5 & 41 \\
\hline & $\%$ & 2.4 & 19.5 & 29.3 & 36.6 & 12.2 & 100.0 \\
\hline \multirow{4}{*}{$\begin{array}{l}>19 \\
\text { years }\end{array}$} & $f$ & 2 & 5 & 1 & 6 & 5 & 19 \\
\hline & $\%$ & 10.5 & 26.3 & $5.3 \%$ & 31.6 & 26.3 & 100.0 \\
\hline & Total $f$ & 3 & 13 & 13 & 21 & 10 & 60 \\
\hline & $\begin{array}{c}\text { Total } \\
\%\end{array}$ & 5.0 & 21.7 & 21.7 & 35.0 & 16.7 & 100.0 \\
\hline
\end{tabular}

TABLE V. Result of Descriptive ANAYLSIS BetweEn Age AND Hab3 (OBvious CHOICE)

\begin{tabular}{|c|c|c|c|c|c|c|c|}
\hline \multicolumn{8}{|c|}{ HAB3 } \\
\hline Age & & \begin{tabular}{|l} 
Strongly \\
Disagree
\end{tabular} & Disagree & Neutral & Agree & $\begin{array}{l}\text { Strongly } \\
\text { Agree }\end{array}$ & Total \\
\hline \multirow{2}{*}{$\begin{array}{l}<19 \\
\text { years }\end{array}$} & $f$ & 4 & 10 & 12 & 5 & 10 & 41 \\
\hline & $\%$ & 9.8 & 24.4 & 29.3 & 12.2 & 24.4 & 100.0 \\
\hline \multirow{4}{*}{$\begin{array}{l}>19 \\
\text { years }\end{array}$} & $f$ & 2 & 2 & 1 & 9 & 5 & 19 \\
\hline & $\%$ & 10.5 & 10.5 & 5.3 & 47.4 & 26.3 & 100.0 \\
\hline & Total $f$ & 6 & 12 & 13 & 14 & 15 & 60 \\
\hline & $\begin{array}{l}\text { Total } \\
\%\end{array}$ & 10.0 & 20.0 & 21.7 & 23.3 & 25.0 & 100.0 \\
\hline
\end{tabular}

As for Table V, the percentages for adolescents below 19 years show an even spread of frequency between agreed (36.6\%), not agreed (34.4\%) and sometimes (29.3\%). Contrasted to the frequency of adolescents below 19 years with above 19 years, the latter apparently seems to agree that SNS is their main medium communication to interact with family, friends and relatives. It could be related to Table VI where a cross tabulation between age with time spend on SNS shows $57.9 \%$ late adolescents use SNS more than two hours in daily basis (refer Table II for frequency of daily basis). They spend more time on SNS which may indicate that SNS is a preferred medium for them to interact with family and friends. This is in line with [32] study where they have found that late 
adolescents adopt SNS platforms in order to (1) communicate with friends who they hardly meet, (2) encouragement from friends who have SNS account, (3) get connected with relatives and families and also (4) planning regular meetings with friends.

TABLE VI. Result of DesCriptive ANAYlsis BetweEn Age AND Time SPEND ON SNS

\begin{tabular}{|c|c|c|c|c|c|c|}
\hline & \multicolumn{3}{|c|}{ Time spend on SNS } & \multirow[b]{2}{*}{ Total } \\
\hline & & & $\begin{array}{c}>30 \\
\text { minutes }\end{array}$ & $\begin{array}{l}1-2 \\
\text { hour }\end{array}$ & $\begin{array}{c}<2 \\
\text { hours }\end{array}$ & \\
\hline \multirow[t]{6}{*}{ AGE } & \multirow[t]{2}{*}{$<19$ years } & $f$ & 13 & 16 & 12 & 41 \\
\hline & & $\%$ & 31.7 & 39.1 & 29.3 & 100.0 \\
\hline & \multirow[t]{2}{*}{$>19$ years } & $f$ & 4 & 4 & 11 & 19 \\
\hline & & $\%$ & 21.1 & 21.0 & 57.9 & 100.0 \\
\hline & & Total $f$ & 17 & 20 & 23 & 60 \\
\hline & & Total \% & 52.8 & 60.1 & 38.3 & 100.0 \\
\hline
\end{tabular}

\section{SNS Addiction}

This section discusses the findings for SNS addiction part. Six questions on SNS addiction were highlighted in the survey which were adopted from [34].

ADT1. I spend a lot of time thinking about social networking sites or planning to use it. (Salience)

ADT2. I urge to use social networking sites more and more. Urge means strong desire to use social networking sites. (Tolerance)

ADT3. I use social networking sites in order to forget about personal problem. (Mood modification)

ADT4. I tried to cut down on the use of social networking sites without success. (Relapse)

ADT5. I become restless or troubled if I have been prohibited from using social networking sites. (Withdrawal)

ADT6. I used social networking sites so much that it has had a negative impact on my studies. (Conflict)

Each question portrays the six core symptoms of addiction such as salience, tolerance, mood modification, relapse, withdrawal, and conflict. Fig. 8 demonstrate the result of overall descriptive analysis on construct SNS addiction with items ranged from Very Rarely (1) to Very Often (5). Based on the table, salience (ADT1), tolerance (ADT2) and relapse (ADT4) show an even spread of percentages between rarely and often. However, mood modification (ADT3), withdrawal (ADT5) and conflict (ADT6) show a slightly different patterns from the former three symptoms. The respondents are actually rarely and only sometimes experienced the symptoms. For withdrawal, $53 \%$ of total respondents rarely use SNS to forget personal problems, and only $28.3 \%$ sometimes felt that SNS is actually a space of escapism to forget about personal problems. While, $51.7 \%$ of respondents rarely thought that SNS actually gave a negative impact on their studies. However, though the often scale of percentages for six symptoms is not that high compared to rarely scale of percentages, majority of the respondents chose sometimes scale for each of the symptoms. Sometimes may lead to often if SNS is used excessively without control.

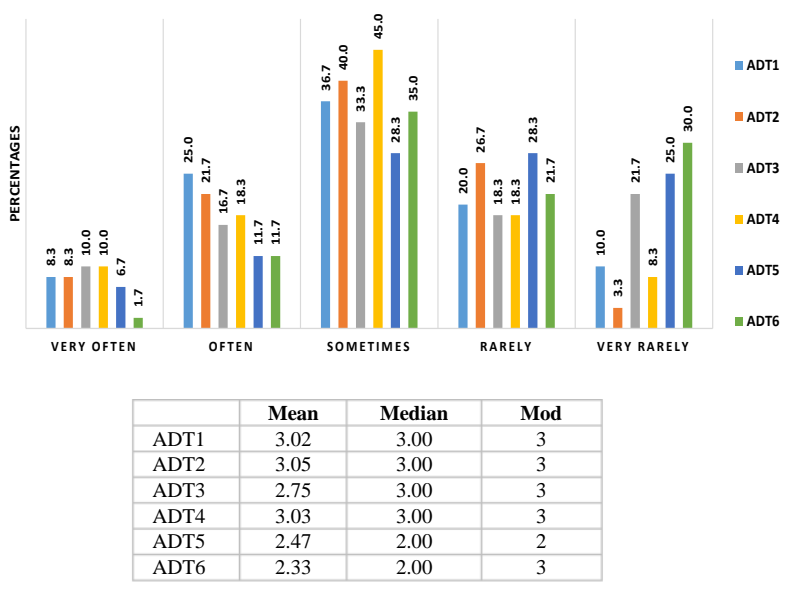

Fig. 7. Result of Overall Descriptive Analysis on SNS Addiction.

Table VII until Table X further analyze the SNS addiction symptoms according to the levels of age. By differentiate between levels of age (below 19 years and above 19 years), an added possibility may be projected. Table VII shows a cross tabulation result between salience and age. Salience means even when they are not engaging with the SNS, they will continuously keep on thinking about using it [28]. Adolescents below 19 years seem to either rarely $(34.1 \%)$ or sometimes (43.9\%) thinking about using SNS or planning on using it compared to those who are above 19 years where $57.9 \%$ of the respondents are actually often thought about using and planning to use the SNS. The same occurred for tolerance as depicted in Table VIII, where adolescents below 19 years rarely $(39 \%)$ or sometimes $(41.5 \%)$ have the ability to tolerate in spending huge amount of time using the SNS. This is different than adolescents above 19 years where $52.6 \%$ of them often and $36.8 \%$ sometimes have strong desire to spend more time using the SNS.

TABLE VII. CROSS TABULATION BETWEEN AGE AND ADT1 (SALIENCE)

\begin{tabular}{|l|l|l|l|l|l|l|l|}
\hline \multicolumn{2}{|c|}{ ADT1 } & \multicolumn{7}{|c|}{$\begin{array}{l}\text { Very } \\
\text { Rarely }\end{array}$} & Rarely & Sometimes & Often & $\begin{array}{l}\text { Very } \\
\text { Pften }\end{array}$ & Total \\
\hline \multirow{3}{*}{$<19$ years } & $f$ & 3 & 11 & 18 & 6 & 3 & 41 \\
\cline { 2 - 9 } & $\%$ & 7.3 & 26.8 & 43.9 & 14.6 & 7.3 & 100.0 \\
\hline \multirow{3}{*}{$>19$ years } & $f$ & 3 & 1 & 4 & 9 & 2 & 19 \\
\cline { 2 - 9 } & $\%$ & 15.8 & 5.3 & 21.1 & 47.4 & 10.5 & 100.0 \\
\hline \multirow{2}{*}{} & Total $f$ & 6 & 12 & 22 & 15 & 5 & 60 \\
\cline { 2 - 8 } & $\begin{array}{l}\text { Total } \\
\%\end{array}$ & 10.0 & 20.0 & 36.7 & 25.0 & 8.3 & 100.0 \\
\hline
\end{tabular}

$* f=$ frequency 
TABLE VIII. CRoss Tabulation Between Age And AdT2 (Tolerance)

\begin{tabular}{|l|l|l|l|l|l|l|l|}
\hline \multicolumn{7}{|l|}{ ADT2 } & \multicolumn{7}{|l|}{$\begin{array}{l}\text { Very } \\
\text { Rarely }\end{array}$} & Rarely & Sometimes & Often & $\begin{array}{l}\text { Very } \\
\text { Often }\end{array}$ & Total \\
\hline \multirow{3}{*}{$<19$ years } & $f$ & 2 & 14 & 17 & 5 & 3 & 41 \\
\cline { 2 - 8 } & $\%$ & 4.9 & 34.1 & 41.5 & 12.2 & 7.3 & 100.0 \\
\hline \multirow{3}{*}{$>19$ years } & $f$ & 0 & 2 & 7 & 8 & 2 & 19 \\
\cline { 2 - 8 } & $\%$ & 0.0 & 10.5 & 36.8 & 42.1 & 10.5 & 100.0 \\
\hline & Total $f$ & 2 & 16 & 24 & 13 & 5 & 60 \\
\cline { 2 - 8 } & $\begin{array}{l}\text { Total } \\
\%\end{array}$ & 3.3 & 26.7 & 40.0 & 21.7 & 8.3 & 100.0 \\
\hline
\end{tabular}

Relapse as can be seen in Table IX shows the percentages of respondents above 19 years where some of them have tried to make several attempts to reduce the usage of SNS but fail to do so (sometimes: $31.6 \%$ and often: $31.6 \%$ ). In contrast, different pattern appears in conflict as shown in Table X. It shows that adolescents from both levels of age do not think that using SNS have negative impact on their studies.

In general, the patterns show that most of the respondents, regardless their age, sometimes experience the six symptoms when using the SNS. Comparing the results of respondents age of 19 years old and above with those below 19 years old, it shows that adolescents below 19 years old have experienced all the six core symptoms either rarely or sometimes compared to those above 19 years old where majority of them either sometimes or often experience the core symptoms. Even though most of the respondents are more likely to seldom experience the symptoms while using the SNS, what is more concern is actually on the ones that are frequently experience addiction symptoms. Based on the data value, 5 to 6 respondents are actually encountering the symptoms (they have chosen either often scale or very often scale at each of the addiction behavior) and it is recommended to further discuss before it prevails any negative impact to the adolescents.

TABlE IX. Cross Tabulation Between Age AND Adt4 (Relapse)

\begin{tabular}{|l|l|l|l|l|l|l|l|}
\hline \multicolumn{7}{|l|}{ ADT 4} & \multicolumn{7}{|l|}{$\begin{array}{l}\text { Very } \\
\text { Rarely }\end{array}$} & Rarely & Sometimes & Often & $\begin{array}{l}\text { Very } \\
\text { Often }\end{array}$ & Total \\
\hline \multirow{3}{*}{$<19$ years } & $f$ & 4 & 7 & 21 & 5 & 4 & 41 \\
\cline { 2 - 9 } & $\%$ & 9.8 & 17.1 & 51.2 & 12.2 & 9.8 & 100.0 \\
\hline \multirow{3}{*}{$>19$ years } & $f$ & 1 & 4 & 6 & 6 & 2 & 19 \\
\cline { 2 - 8 } & $\%$ & 5.3 & 21.1 & 31.6 & 31.6 & 10.5 & 100.0 \\
\hline & Total $f$ & 5 & 11 & 27 & 11 & 6 & 60 \\
\cline { 2 - 8 } & $\begin{array}{l}\text { Total } \\
\%\end{array}$ & 8.3 & 18.3 & 45.0 & 18.3 & 10.0 & 100.0 \\
\hline
\end{tabular}

$*_{f=\text { frequency }}$
TABlE X. Cross Tabulation Between Age and Adt6 (Conflict)

\begin{tabular}{|c|c|c|c|c|c|c|c|}
\hline \multicolumn{8}{|l|}{ ADT6 } \\
\hline Age & & $\begin{array}{l}\text { Very } \\
\text { Rarely }\end{array}$ & Rarely & Sometimes & Often & $\begin{array}{l}\text { Very } \\
\text { Often }\end{array}$ & Total \\
\hline \multirow{2}{*}{$<19$ years } & $f$ & 12 & 12 & 12 & 4 & 1 & 41 \\
\hline & $\%$ & 29.3 & 29.3 & 29.3 & 9.8 & 2.4 & 100.0 \\
\hline \multirow{4}{*}{$>19$ years } & $f$ & 6 & 1 & 9 & 3 & 0 & 19 \\
\hline & $\%$ & 31.6 & 5.3 & 47.4 & 15.8 & 0.0 & 100.0 \\
\hline & Total $f$ & 18 & 13 & 21 & 7 & 1 & 60 \\
\hline & $\begin{array}{l}\text { Total } \\
\%\end{array}$ & 30.0 & 21.7 & 35.0 & 11.7 & 1.7 & 100.0 \\
\hline
\end{tabular}

These findings might further indicate that there are adolescents who might experience some of the habit or addiction symptom on the SNS usage even though it is only minor. Overall result shows that older adolescents (aged above 19 years) have developed habit on using SNS compared to younger adolescents (aged below 19 years). The similar patterns were seen in addiction as well where older adolescents seem to have more symptoms appeared. It is in line with the higher percentage of SNS as a preferred choice of medium communication and time spend on using SNS, where most of them have used the SNS more than two hours per day. In general, therefore, it seems that stronger SNS engagement were identified among the older adolescents which shows that it is important to understand the habitual and addiction phenomena on SNS usage at early stage. Before the younger adolescents become older and have the same experience of SNS engagement, it is worth to understand factors that influenced the SNS habit and addiction behavior. However, a bigger sample is needed for researcher to see the patterns of the SNS usage in order to further analyze the habit or addiction behavior. It would be also significant if some further insights can be obtained to see what factors that actually triggers the habit and addiction behavior and how does it triggers.

\section{CONCLUSION}

This study evaluates and examines SNS usage behavioural which is habit and addiction among adolescents in Malaysia, specifically in Klang Valley. Based on the online survey, this study offers some important remarks on how essential it needs to be pursued. Looking at the findings, it can be concluded that adolescents in Malaysia (in this study specifically in Klang Valley) experienced habit and addiction. Although all the core symptom may not appear and mostly were found in older adolescents, this study is hoped to attract attention of the scholars and shed some light on the niche area. A further study with more focus on the factors that influenced the younger adolescents to use SNS are needed because apparently they will get older and might develop the habit and addiction behavior in time. Future studies with bigger sample and advanced statistical analysis is also recommended. 


\section{ACKNOWLEDGMENT}

This study is funded by research grant under Universiti Teknologi Malaysia (UTM) Research University Grant (RUG) with Vote No. 14J78. Thank you also to the Ministry of Higher Education Malaysia and UTM Research Management Team for the continuous supports.

\section{REFERENCES}

[1] Internetworldstats, "Asia Internet Usage Stats Facebook and Population Statistic," 2015.

[2] R.S.Kamini, "Malaysia faces growing Internet addiction threat," The Rakyat Post, 2014, pp. 5-7.

[3] Hootsuite, "Digital in 2017: Southeast Asia." [Online] Available: http://www.slideshare.net/wearesocialsg/digital-in-2017-southeast-asia? ref=https://aseanup.com/southeast-asia-digital-social-mobile. [Accessed: 18-Dec-2017].

[4] W. Shin, and N. Ismail, "Exploring the role of parents and peers in young adolescents' risk taking on social networking sites," Cyberpsychology, Behavior, and Social Networking, vol. 17, no. 9, pp. 578-583, 2014.

[5] M. Mäntymäki and A. K. M. N. Islam, "The Janus face of Facebook: Positive and negative sides of social networking site use," Computers in Human Behavior, vol. 61, pp. 14-26, 2016.

[6] T. K. H. Chan, C. M. K. Cheung and Z. W. Y. Lee Mr, "Transition from Urge to Excessive Use of Social Networking Sites: The Moderating Role of Self- Control and Accessibility," Pacific Asia Conference Information Systems (PACIS), 2015.

[7] M. D. Griffiths, "Social networking addiction: Emerging themes and issues," Journal of Addiction Research \& Therapy, vol. 4, no. 5, pp. 4-5, 2013.

[8] P. M. Valkenburg, J. Peter and A. P. Schouten, “ Friend Networking Sites and Their Relationship to Adolescents' Well-Being and Social Self-Esteem," CyberPsychology \& Behavior, vol. 9, no. 5, pp. 584-590, 2006.

[9] I. Ozer, A. C. Karpinski and P. A. Kirschner, "A Cross-cultural Qualitative Examination of Social-networking Sites and Academic Performance," Procedia - Social and Behavioral Sciences, vol. 112, pp. 873-881, 2014.

[10] S. Lee, "Analyzing Negative Social Networking Sites Behaviors of Elementary and Middle School Students in Korea," Computers in Human Behavior, vol. 43, pp. 15-27, 2015.

[11] K. ISIS, "Survey on the Internet Usage (2012)," 2013.

[12] B. Subramaniam, "On the Social Media Circuit," The Star Online, [Online] Available: https://www.thestar.com.my/news/education/ 2014/ 01/05/on-the-social-media-circuit. [Accessed: 12-Jul-2017].

[13] Statista, "The Statistics Portal." [Online] Available: https://www.statista.com/statistics/199242/social-media-and networking-sites-used-by-us-teenagers. [Accessed: 12-Jul-2017].

[14] S. Pillay, "Suicide on the Rise among Malaysian Youth," The Star Online, [Online] Available: https://www.nst.com.my/news/exclusive/ 2017/05/243354 /suicide-rise-among-malaysian-youth. [Accesssed: 28May-2018].

[15] H. Aarts and A. Dijksterhuis, "Habits as knowlegde structures: Automicity in Goal Director Behaviour," Journal of Personality and Social Psyschology2, vol. 78, no. 1, pp. 53-63, 2000.

[16] B. Verplanken and H. Aarts, "Habit, Attitude, and Planned Behaviour: Is Habit an Empty Construct or an Interesting Case of Goal-directed Automaticity?," European Review of Social Psychology, vol. 10, no. September, pp. 101-134, 1999.

[17] S. Lee and J. Jahng, "Tense moods make you use habitually facebook: A new framework for habitual IT use based on the mechanisms of mood regulation," 19th Americas Conference on Information Systems,
AMCIS 2013 - Hyperconnected World: Anything, Anywhere, Anytime, vol. 4, pp. 3187-3195, 2013.

[18] M. Limayem and S. Hirt, "Force of Habit and Information Systems Usage: Theory and Initial Validation," Journal of the Association for Information Systems, vol. 4, pp. 65-95, 2003.

[19] G. L. Polites and E. Karahanna, "Shackled to the Status Quo: The Inhibiting Effects of Incumbent System Habit, Switching Costs, and Inertia on New System Acceptance," MIS Quarterly, vol. 36, no. 1, pp. 21-42, 2012.

[20] J. Cabinakova, J. Kroenung, A. Eckhardt and S. Bernius, "The importance of culture, trust, and habitual patterns: determinants of crosscultural egovernment adoption," 21st European Conference on Information Systems (ECIS 2013), p. 13, 2013.

[21] D. L. Ronis, J. F. Yates and J. P. Kirscht, "Attitudes, decisions, and habits as determinants of repeated behavior," Attitude structure and function, pp. 213-239, 1989.

[22] D. T. Neal, W. Wood, J. S. Labrecque and P. Lally, "How do habits guide behavior? Perceived and actual triggers of habits in daily life," Journal of Experimental Social Psychology, vol. 48, no. 2, pp. 492498, 2012.

[23] M. Limayem, S. G. Hirt and C. M. K. Cheung, "How habit limits the predictive power of intention: The case of IS continuance," MIS Quarterly, vol. 31, no. 4, pp. 705-737, 2007.

[24] W. K. Lee, "The temporal relationships among habit, intention and IS uses," Computers in Human Behavior, vol. 32, pp. 54-60, 2014.

[25] O. Turel and A. Serenko, "The benefits and dangers of enjoyment with social networking websites," European Journal of Information Systems, vol. 21, no. 5, pp. 512-528, 2012.

[26] H. Xu and B. Tan, "Why do I Keep Checking Facebook: Effects of Message Characteristic on the Formation of Social Network Services Addiction," Thirty Third International Conference on Information Systems, pp. 1-12, 2012.

[27] R. LaRose and M. S. Eastin, "A Social Cognitive Theory of Internet Uses and Gratifications: Toward a New Model of Media Attendance A Social Cognitive Theory of Internet Uses and Gratifications : Toward a New Model of Media Attendance," Journal of Broadcasting \& Electronic Media, vol. 48, no. 3, pp. 358-377, 2004.

[28] M. D. Griffiths, "A "components" model of addiction within a biopsychosocial framework," Journal of Substance Use, vol. 10, no. 4, pp. 191-197, 2005.

[29] E. Guedes, A. E. Nardi, F. M. C. L. Guimarães, S. Machado, and A. L. S. King, "Social networking, a new online addiction: a review of Facebook and other addiction disorders," Medical Express, vol. 3, no. 1, pp. 1-6, 2016.

[30] P. S. Gamito, D. G. Morais, J. G. Oliveira, R. Brito, P. J. Rosa, M. Gaspar and D. Matos, "Frequency is not enough: Patterns of use associated with risk of Internet addiction in Portuguese adolescents," Computers in Human Behavior, vol. 58, pp. 471-478, 2016.

[31] D. J. Kuss, and M. D. Griffiths, "Online social networking and addiction-A review of the psychological literature," International Journal of Environmental Research and Public Health, vol. 8, no. 9, pp. 35283552, 2011.

[32] H. Kefi, A. Mlaiki, and M. Kalika, "Social Networking Continuance : When Habit leads to information overload," ECIS 2015 Proceedings, pp. $1-13,2015$.

[33] X. Lin, M. Featherman and S. Sarker, "Understanding Factors Affecting Users' Social Networking Site Continuance: A Gender Difference Perspective," Information \& Management, vol. 54, no. 3, pp. 383-395. 2017.

[34] C. S. Andreassen, T. Torsheim, G. S. Brunborg and S. Pallesen, "Development Of A Facebook Addiction Scale," Psychological Reports, $\begin{array}{lllll}\text { vol. } 110, & \text { no. } 2, & \text { pp. } & \text { 501-517, } & \end{array}$ 